\title{
RECORRIENDO MADRID. UNA CRISTIANA Y LA PRUEBA DE EMILIA PARDO BAZÁN ${ }^{1}$
}

\author{
Rocío CHARQUES GÁMEZ \\ Université de Pau et des Pays de l'Adour
}

\section{RESUMEN}

En Una cristiana y La prueba Emilia Pardo Bazán enmarca la historia de sus personajes en los espacios típicos de su obra de creación: Galicia y Madrid. En este trabajo analizamos la presencia del espacio urbano, en concreto de la capital española, en estas novelas. Los espacios públicos y los espacios privados son dos aspectos fundamentales en los que nos detendremos en este estudio.

Palabras clave: espacio urbano, Madrid, Emilia Pardo Bazán, novela XIX, Una cristiana-La prueba.

\section{ABSTRACT}

In Una Cristiana and La prueba Emilia Pardo Bazán introduces her characters' story in the typical spaces that she uses in her creative works: Galicia and Madrid. In this article we study the presence of urban space, particularly Madrid, in these novels. Public spaces and private spaces are two main aspects that we analyze in this article. Key words: urban space, Madrid, Emilia Pardo Bazán, 19th century novel, Una cristiana-La prueba.

Madrid, siempre visto a través de los ojos de los artistas en distintos periodos y circunstancias, constituye de por sí un objeto de estudio y, desde hace unos

1. El presente trabajo se enmarca en el proyecto de investigación I+D subvencionado por el Ministerio de Ciencia e Innovación «Ediciones y estudios sobre la obra literaria de Emilia Pardo Bazán» (FFI2010-18773). 
años, la nueva ola de investigaciones a propósito de la presencia del espacio urbano en la literatura española nos hace volver la vista hacia la capital y, como hicimos tiempo atrás (2006), lo haremos de la mano de Emilia Pardo Bazán. Doña Emilia recrea en algunas de sus narraciones distintos espacios urbanos, ya apuntados por Nelly Clémessy en su clásico estudio sobre la autora Emilia Pardo Bazán como novelista. A este respecto, tal como la estudiosa señala, Pardo Bazán vertebra sus obras en dos ejes espaciales: el eje rural, centrado en Galicia, y el urbano, referido a Madrid y de nuevo a Galicia. Si bien es cierto que otras novelas, como Insolación y Morriña (1889), se prestan más al análisis de la presencia de la capital española en su obra, la elección de Una cristiana y La prueba (1890), publicadas con posterioridad a las otras, viene motivada por dos razones. En primer lugar, al escaso interés de la crítica por estas novelas y, por ende, la poca bibliografía sobre las mismas. Y en segundo término, por constituir esta serie un ejemplo más de la presencia de Madrid en la literatura de la escritora coruñesa ${ }^{2}$. A partir de estas premisas, damos paso a nuestra colaboración en el análisis del espacio urbano en esta serie novelística escrita por Emilia Pardo Bazán.

Las dos novelas constituyen un ejemplo más de cómo nuestra autora, al igual que sus contemporáneos, baste nombrar a Galdós, emplea su pluma en la descripción de ambientes madrileños fundamentales para acercarnos al Madrid de la época, a sus espacios físicos pero también a sus habitantes ${ }^{3}$, aunque en estas novelas la autora se centra en el análisis de las clases medias (Rubio Cremades 2001, pág. 534). En Una cristiana y La prueba la voz narradora se identifica con la del protagonista Salustio, que al final de la serie le muestra a su amigo Portal las memorias que acabamos de leer, con lo que el trasiego por la ciudad viene mediatizado por la visión del mismo. Aunque la voz narradora, evidentemente, se aleja de la objetividad en el relato de los hechos, pues nos quiere describir un estado emocional y demostrar la beatitud de Carmiña, la presencia de los espacios es constante, sobre todo de Madrid, donde tiene lugar la mayor parte de la historia ${ }^{4}$.

2. Penas Varela reflexiona acerca del espacio en la cuentística de Pardo Bazán. En su mención de la aparición de Madrid en los cuentos comenta respecto a la capital española: «El Madrid de los cuentos pardobazanianos es la gran capital de Insolación, Morriña, Una cristiana, La prueba, La Quimera y La Sirena Negra. Y su diversidad como urbe, en sus barrios y viviendas, en sus espacios públicos y privados, visualiza la sociología plural de sus moradores» (2006: 155).

3. «La ciudad no sólo está formada por sus espacios; las personas también forman parte del paisaje urbano» (Peñalta Catalán, 2010: 19).

4. Otros lugares donde se desarrolla la acción son Pontevedra y Ullosa, donde vive la madre de Salustio. Por consiguiente, en las novelas aparecen los dos ejes espaciales preferentes 
Una cristiana nos presenta a Salustio, gallego que parte a la capital para estudiar Ingeniería de Caminos. Los ambientes, por tanto, por los que deambula el protagonista son los típicos de un joven universitario: las posadas madrileñas, en cuya recreación de personajes se deleita el narrador. La presentación de sus huéspedes y regentes, a la vez que las historias acontecidas entre sus paredes, nos recuerdan a las obras sobre estudiantes y sus peripecias, lo que nos remite, inmediatamente, a obras clásicas: «[... ] en fin, todo lo que abunda en este género de guaridas de la villa y corte, mil veces retratadas por los novelistas y pintores de costumbres» (Pardo Bazán, 1956: 535). Igualmente, la preferencia por este tipo de personaje y sus ambientes se evidencia en otras de las obras de Pardo Bazán, baste recordar su primera novela Pascual López cuyo argumento se fundamenta en la vida de un estudiante de Medicina en Santiago de Compostela. Las posadas por las que pasa Salustio son dos, ambas regentadas por mujeres vizcaínas. De hecho, la mayor parte de las casas de huéspedes de la capital están dirigidas por personas procedentes de otros puntos de España que emigran debido a las pocas oportunidades laborales existentes en sus poblaciones. Madrid se presenta como un lugar de oportunidades al que el español de otras zonas acude movido por la situación económica desfavorable de su lugar de origen. Así pues, en las dos casas de la novela, la dueña es una mujer de origen vizcaíno, pero las características de las propietarias y, por tanto, las condiciones en las que tienen sus dependencias distan mucho entre sí. La primera posada en la que vive Salustio se caracteriza por la inmundicia y desorden; en cambio, la segunda, sita en la calle del Clavel, resalta por la limpieza y orden de su dueña. Es en esta segunda residencia donde el protagonista conoce a Luis Portal, personaje fundamental, pues entre ellos surge una buena amistad y a él acude Portal como interlocutor y consejero de su pasión amorosa. Durante las caminatas que realizan por Madrid, Salustio y Portal comparten sus ideas sobre el amor y sobre la vida. A pesar de tener las mismas opiniones, en varias ocasiones, vemos cómo en lo referente a la concepción de la mujer sus reflexiones son divergentes, produciéndose una distorsión en su convivencia. Estos paseos suelen desarrollarse en los lugares próximos a la posada, por eso los vemos deambular por la calle del Clavel y por la del Turco. Otro de los lugares favoritos de los estudiantes se encuentra en el viaducto, conocido como suicidadero, donde se venden libros al aire libre y desde donde se disfruta de una vista privilegiada de la ciudad. Esta visión, como siempre a partir de los ojos del narrador-protagonista, Salustio, se detiene en cinco

en la obra literaria de nuestra autora. Por otro lado, Santiáñez-Tió estudia la importancia de la voz narrativa de esta obra. 
enclaves urbanos: el palacio de Uceda, la torre mudéjar de San Pedro, el Manzanares, el Guadarrama y la calle de Segovia, cuya profundidad les seduce al igual que a los suicidas que se lanzan al abismo desde este lugar. Leemos en el capítulo XX de Una cristiana:

La tarde, de magnífica serenidad, convidaba a arrimarse al alto enverjado y admirar al través de sus huecos el punto de vista, acaso el más hermoso de Madrid. Sin entretenernos en resolver los libros viejos, de texto la mayor parte, mugrientos y maltratados casi todos, que vendía al aire libre y sobre el santo suelo un vejete con facha de maniático, aproximamos la cara a los hierros y nos embelesamos en mirar primero el grandioso panorama de la izquierda, el rojo palacio de Uceda con sus blancos escudos a que sirven de tenantes fieros leones, las mil cúpulas y rotondas de templos y casas que domina, esbelta como la palmera, la torre mudéjar de San Pedro. Luego nos volvimos hacia la derecha, encantados por la fresca verdura del jardinete que a gran distancia debajo de nosotros extendía un tapete de coníferas y arbustos en flor. Allá a lo lejos, el Manzanares trazaba sobre las verdes praderas una ese de metal blanco, y el Guadarrama erguía su línea blanca y refulgente detrás de los severos y escuetos contornos de las sierras próximas. Pero lo que nos fascinaba, la nota sublime de aquel conjunto, era la calle de Segovia, a pavorosa profundidad, abajo, abajo...

En este mismo lugar los protagonistas coinciden con otro huésped de la casa de la vizcaína, el cubano Trinitos, que se convertirá más adelante en crítico teatral. Él será, precisamente, quien les acompañe al teatro Real a ver una ópera de la que el cubano saldrá malhumorado debido a la nefasta calidad del espectáculo. De allí los tres se dirigirán al café Fornos a tomar un ponche, pero la velada nocturna acabará mal para Salustio, pues un enfriamiento le postrará en cama, dejándole convaleciente en casa de sus tíos Felipe y Carmiña, con quienes vive. En su delirio, causado por la fiebre, Salustio creerá que su tía le confiesa su amor por él.

Hasta este momento, nos hemos detenido en los ambientes estudiantiles madrileños en la primera parte de la serie novelística. La segunda parte también recoge otros recorridos, pues tras la recuperación de Salustio, los dos amigos caminan desde las calles de Serrano y Lista hasta el paseo de la Castellana. De nuevo, los estudiantes se ponen al día de sus emociones. Salustio le informa de la evolución de sus amores con la tía, mientras que Portal nos pone al corriente de su encuentro con la inglesa Mo, y su enamoramiento. A partir de entonces, la narración contrapone dos tipos de mujer bien diferenciados: Carmiña, ejemplo de la mujer tradicional y cristiana ideal, según Salustio, y Mo, paradigma de la mujer moderna y nueva, perfecta para Portal. En ambos casos, la presentación de la mujer amada es subjetiva pero sirve para presentar dos clases de mujeres diametralmente opuestas y enfrentadas entre 
sí. En este aspecto, Portal resultará ser mucho más moderno y progresista que Salustio, quien desde el punto de vista sentimental prefiere un ideal de mujer que contrasta con el resto de su ideario. No vamos a detenernos en el análisis de este aspecto, pues ha sido uno de los puntos más comentados con respecto a estas novelas desde el punto de vista de la crítica feminista ${ }^{5}$ y nos apartaría del contenido y enfoque de nuestro estudio.

En Una cristiana conviene señalar otros espacios urbanos no vinculados con el ambiente de los estudiantes y que se relacionan con los otros personajes. Por ejemplo, en el caso del tío de Salustio, Felipe, nos aproximamos al Hotel de los Embajadores donde reside este hasta el cambio de su domicilio en su nueva casa de la calle Claudio Coello, donde vivirá con su futura esposa y, posteriormente, con su sobrino Salustio. El tío, hacendado cuyos orígenes judíos provocan la animadversión tanto del protagonista como de su madre, costea los estudios de su sobrino a quien recibirá en su casa para recortar los gastos que le suponen su estancia en posadas. Hacia allí se dirige el sobrino utilizando el tranvía que toma en la Puerta del Sol. De este modo, la Puerta del Sol se erige como otro punto de referencia por el que transitan los personajes, así como también la calle Ancha de San Bernardo, donde, como es bien sabido, Emilia Pardo Bazán vivió a partir de la década de los 906. En la calle del Rubio se sitúa, dentro de la historia, la casa donde reside la prostituta Belén, otro de los personajes femeninos enfrentados a Carmiña y que concederá sus favores amorosos al protagonista en los momentos de decepción sentimental. En La prueba el tranvía también aparece como un elemento recurrente de gran trascendencia, pues permitirá el encuentro entre Portal y Mo. Por supuesto, el tranvía no puede faltar en las narraciones ambientadas en Madrid, pues supone una auténtica revolución en los medios de transporte en el siglo XIX y pasará a ser uno de los protagonistas de la vida madrileña ${ }^{7}$. En La prueba Portal

5. Por ejemplo, Maryellen Bieder (1998) o Carlos Feal (1982), este último también desde el punto de vista de la religión. Sobre el feminismo de Pardo Bazán puede consultarse el trabajo de Adna Rosa Rodríguez (1991) o la edición de textos feministas de Pardo Bazán hecha por Gómez-Ferrer (1999).

6. La autora enmarca sus obras en el espacio madrileño que conoce como, en este caso, su calle, con protagonismo también en otras novelas. Ermitas Penas (2005: 285) puntualiza que en Morriña la acción tiene lugar mayoritariamente en espacios interiores. Además advierte que son escasas las descripciones de los espacios, pero hay una excepción: la calle Ancha de San Bernardo se describe con mayor detenimiento y aunque el ilustrador de la novela, Cabrinety, no dibuja el famoso tranvía, sí que incluye cinco viñetas donde aparece esta calle.

7. De hecho, Emilia Pardo Bazán lo presenta en muchas partes de sus obras de creación, como, por ejemplo, en el cuento En el tranvía, cuya acción transcurre en él y en el que la voz narradora nos presenta dos clases sociales bien diferenciadas: la clase alta, que 
conoce a Mo durante el trayecto que emprende de vuelta a la posada tras uno de sus frecuentes paseos diarios. En la Puerta del Sol el personaje masculino toma el tranvía para dirigirse a la calle Fuencarral y bajar en la glorieta de Bilbao. Es en la parada de la Puerta del Sol donde ve por primera vez a Mo, que lleva en sus manos una edición de Romeo y Julieta. El flechazo es inmediato y Portal decide conquistarla. Observa que la joven sale del tranvía al llegar al Tribunal de Cuentas ya que su domicilio se sitúa en una calle solitaria cercana a la parada. Una vez que la ha conocido un poco más en sus encuentros en el tranvía, le propone acompañarla dando un paseo, desplazándose así, juntos, a la iglesia de Chamberí. En contraposición a la mujer tradicional española, y a Carmiña, en particular, Mo trabaja y todos los días da clases a las hijas de una familia rica que vive en la calle Ancha de San Bernardo. De nuevo se menciona esta calle en la que predomina un tipo de población de clase social alta. Los cambios de escenario, por tanto, se suceden a lo largo de la narración y los ambientes se mezclan ofreciendo al lector una galería de personajes y espacios amplios y diversos. Los recorridos, bien a pie o bien en tranvía, son continuos y nos muestran una ciudad dinámica así como también proporcionan acción y movimiento a la historia. Por ejemplo, cuando el protagonista comienza a perseguir a su tía en una de sus salidas pensando que se dirigirá hacia la misa de las Pascualas, descubre que cuando pasan de la calle Jorge Juan a la plaza Colón, ella no continúa por Prado, sino que emprende la subida de la Ronda de Recoletos para ir a la calle Almagro. Luego a la del Cisne y, finalmente, doblar hacia Chamberí. Se trata de un trasiego urbano incoherente que está motivado por el deseo de aturdir a su sobrino. En otros momentos, los paseos sirven para descubrir el pensamiento de los personajes, pues cuando Salustio va en compañía de una persona se entabla un diálogo interesante en este aspecto.

En lo que respecta a los espacios privados, refiriéndonos siempre a los episodios que transcurren en Madrid, además de las posadas y la casa de Felipe, cabe citar las casas de la señora de Barrientos, la del republicano Alejo Nevada y aquellas en las que vive Belén. Las dos primeras, por tanto, pertenecen a clases acomodadas, mientras que las segundas son las de una muchacha de condición bien distinta cuyo destino no le proporciona ningún tipo de estabilidad. En un principio vive en una casa en la calle del Rubio con su hermana y otras mujeres. Espacio privado que utilizan como taller a fin de preparar regalos hechos de papel y destinados, posteriormente. a la venta para la celebración de conmemoraciones. Después se mudará a una casa más lujosa gracias a

conforman la mayoría de los viajeros de la línea, y la baja, representada por una desgraciada mujer abandonada que lleva a su hijo ciego en brazos. 
su relación con uno de sus amantes, pero de esta situación disfrutará por poco tiempo debido al abandono que sufrirá de este nuevo amante. Su vida disoluta contrasta con la de la señora de Barrientos y sus hijas, a las que la madre proporciona el tipo de educación enraizado en el clásico concepto de la época conocido como «el ángel del hogar». Pese a ello una de las hijas fracasará en su matrimonio y se desviará del camino marcado. La presentación de los personajes en sus ambientes es fundamental para entenderlos y estos se retratan a lo largo de la narración. El destino de la mujer es una de las cuestiones que más preocupan a doña Emilia, y fundamentalmente lo que respecta a su educación ${ }^{8}$, por lo que el retrato devastador de la mujer de la época se presenta en las páginas de sus escritos, como en el caso que nos ocupa. Por otro lado, Salustio también frecuenta la casa de Alejo Nevada, donde se realiza la pintura de ambientes políticos, pintura completada por las que tienen lugar en Galicia con motivo de las incursiones políticas del tío en las que se ve envuelto Salustio en una de sus estancias en Pontevedra.

Hasta el momento contamos, pues, diversas recreaciones de la vida madrileña vinculadas con la presentación del espacio: las zonas de estudiantes, las de las clases altas, los espacios privados de mujeres y los espacios privados con debate político. A ellas se unen también otros como son los espacios religiosos con su representante el padre Moreno e, incluso, los relacionados con la salud, con el médico gallego Sáuco que atiende a Salustio y al fraile. El protagonista conoce al franciscano cuando veranea en Galicia en su camino hacia el Tejo, donde se encuentra la futura familia política del tío. La aparición de este nuevo personaje constituye uno de los momentos más interesantes de las memorias del protagonista. El detallado análisis de las reflexiones que Salustio lleva a cabo sobre su la figura del fraile durante la caminata hacia el Tejo tira por tierra los prejuicios que posee acerca de los representantes eclesiásticos. Su presentación supone una excelente muestra de la maestría de la pluma de Pardo Bazán a la hora de describir a sus personajes partiendo de referencias artísticas ${ }^{9}$, en esta ocasión con comparaciones con las esculturas de San Antonio de Padua, frente a las ideas preconcebidas de Salustio, alimentadas de pinturas clásicas del Museo y la Academia, de Zurbarán e, incluso, de la interpretación de Rafael Calvo en Don Álvaro o la fuerza del sino del duque de Rivas. La fuerte personalidad

8. Sobre este tema existe abundante bibliografía. Cito únicamente dos al respecto, además de las referencias a obras sobre feminismo citadas en la nota 5: el estudio de $\mathrm{M}^{\mathrm{a}}$ Ángeles Ayala Aracil (2001) y mi estudio sobre los artículos feministas de Pardo Bazán en el Nuevo Teatro Crítico (2003).

9. Para ampliar la información respecto a la influencia de las artes en Pardo Bazán consúltese el trabajo de Yolanda Latorre (2002). 
y los avatares del fraile -por cierto, franciscano ${ }^{10}$ - le convierten en uno de los personajes más interesantes y de mayor presencia en la obra. El padre Moreno es el confesor y consultor de Carmiña, al que ella acude en diversos momentos de duda y de necesidad de apoyo. En lo que respecta a la presencia del fraile en Madrid, sabemos que viene causada por la enfermedad que sufre originada, según la opinión de quienes le conocen, por el cambio que supone vivir en Galicia viniendo de un clima cálido como el norte de África. En el hospital de San Carlos se reencuentran los dos personajes y tienen, mientras pasean en una berlina, un nuevo enfrentamiento a causa del convencimiento de Salustio de la infelicidad de su tía y de su pasión hacia él.

Anteriormente señalábamos y conviene recordarlo de nuevo, que los personajes de Una cristiana también se mueven por círculos artísticos, como el Teatro Real donde Portal y Salustio asisten a la representación de una ópera. En La prueba, en cambio, Saúco y Salustio asisten a una representación en el teatro Apolo, en el que actúa la hermana de Belén, hecho que motiva la próxima y última visita del protagonista a su amante ocasional. En la primera ocasión, las reacciones que provoca la ópera surgen de Trinito, tal como apunta Salustio. El cubano no sufre la deficiente actuación e insta a sus compañeros a abandonar la sala. En lo que respecta al teatro, no existe ningún apunte del tipo de espectáculo, sino que el narrador solo se fija en el impacto que la visión de la hermana de su amante provoca en él, así como en el inmediato interés en volver a ver a Belén en un momento de desestabilidad emocional. En este apartado de nuestro estudio conviene tener presente el interés de doña Emilia como espectadora y crítica de representaciones teatrales así como de amante de la ópera ${ }^{11}$. En muchos de sus personajes se encuentra reflejado este aspecto y entre sus obras se rastrea esta presencia, ya desde sus primeros escritos de creación como en la novela breve La dama joven, o en otros posteriores como Por el arte $^{12}$. Desde luego, este es otro de los elementos que componen el espacio de la urbe y que Pardo Bazán conoce de primera mano.

La lectura de estas dos novelas nos descubre la recreación de los espacios principales dentro de la obra de nuestra escritora: Galicia y Madrid. En este

10. El interés de doña Emilia por la orden franciscana de la que forma parte es bien conocida. De hecho, uno de sus primeros trabajos se dedica al estudio del fundador San Francisco de Asís. Sobre el franciscanismo de Pardo Bazán consúltese el trabajo de Patiño Eirín (2001).

11. En 2007, especialistas de Pardo Bazán se reunieron en la Casa-Museo de la autora con motivo del IV Simposio «Emilia Pardo Bazán: Emilia Pardo Bazán y las artes del espectáculo» (2008).

12. La pardobazanista Cristina Patiño Eirín ha estudiado los modelos de los que se sirve doña Emilia en Por el arte (2009). 
último doña Emilia ha pasado a fijar su residencia y su conocimiento de la ciudad se demuestra en páginas como las que acabamos de comentar. El recorrido por las calles madrileñas viene de la mano del narrador-protagonista, Salustio, que siendo estudiante nos llevará por los ambientes típicos de los universitarios que llegan de otras partes de España. Las posadas constituyen el primer lugar en el que se sitúa la historia. En estos momentos se delinea el tipo de vida clásico del estudiante, las peripecias que experimenta en la villa y los amigos que encuentra a su paso, con clara referencia a una larga tradición literaria ya comentada. Las dueñas de estos establecimientos en Madrid suelen ser mujeres de otras regiones, como las vizcaínas que se presentan en estas páginas, con cualidades contrapuestas entre sí (una será sucia y desordenada mientras la otra se caracterizará por la limpieza y pulcritud). Después conviene indicar los paseos a pie que Salustio suele hacer, en general en compañía de su amigo Portal. Las salidas por el centro de Madrid se completan con la asistencia a espectáculos en teatros como el Real y el Apolo, así como con los cafés de Fornos o el Café de Levante. Con la aparición del tío del protagonista en la historia los espacios descritos se amplían, desplazándose hacia los propios de las clases sociales altas. De este modo, la primera visita que realiza a su tío le lleva al hotel de los Embajadores, y más tarde a su casa, en la calle Claudio Coello, en la que el protagonista pasará a vivir con él y con su esposa. Asimismo, el transporte constituye uno de los elementos indispensables a la hora de retratar el Madrid de entonces por lo que el tranvía hace acto de presencia en diversos momentos de la historia. Otros espacios que hemos remarcado a lo largo de nuestro trabajo son los privados que están ligados, en general, a clases burguesas como pueden ser la casa de los tíos, la de la señora Barrientos o la de un importante político. No obstante, asoma en la descripción de estas casas una que pertenece a una clase social baja: el domicilio de Belén. Su introducción no se desliga del ambiente retratado porque los hombres de clases acomodadas visitan a las mujeres de posición social inferior para satisfacer sus deseos. De hecho, el protagonista conoce a Belén cuando acompaña a su tío Felipe en una de sus asiduas visitas a la casa y él mismo se aprovechará de la joven en varias ocasiones. Madrid aparece ante nuestros ojos desde la visión de un joven gallego estudiante en la Escuela de Caminos cuya obsesión amorosa arrastrará a un torbellino de pasiones insatisfechas. Sus pasos no traspasan grandes fronteras de clase, pues son los típicos de un estudiante de su edad y condición. En definitiva, hemos observado cómo el espacio urbano contribuye a proporcionar movimiento y acción a la historia, así como a explicar a los mismos personajes, sobre todo en su relación con los espacios privados. 


\section{BIBLIOGRAFÍA}

Ayala Aracil, María de los Ángeles, «Emilia Pardo Bazán y la educación femenina», Salina. Revista de Lletres, no 15, noviembre 2001, pp. 183-90.

BIEDER, Maryellen, «Emilia Pardo Bazán y la emergencia del discurso feminista», en ZaVAla, Iris M. (coord.), Breve historia feminista de la literatura española. Volumen V: La literatura escrita por mujeres (Del siglo XIX a la actualidad), Universidad de Puerto Rico, Anthropos, 1998, pp.75-110.

Charques GÁmez, Rocío, Los artículos feministas en el Nuevo Teatro Crítico de Emilia Pardo Bazán, Centro de Estudios sobre la Mujer de la Universidad de Alicante, Cuadernos de Trabajos de Investigación, 5, 2003.

Charques GÁmez, Rocío, «Retrato de Madrid en Insolación, de Emilia Pardo Bazán», en VAldiviESO, Jorge H. y L. Teresa VAlDVIESO (eds.), Madrid en la Literatura y las Artes, Arizona, Editorial Orbis Press, Serie Reflexión, no 11, 2006, pp. 38-45.

Clemessy, Nelly, Emilia Pardo Bazán como novelista. De la teoría a la práctica, Madrid, Fundación Universitaria Española, 1981.

FEAL, Carlos, «Religión y feminismo en la obra de Emilia Pardo Bazán», en AMOR y VÁzQuez, José y A. David Kossoff (eds.), Homenaje a Juan López Morillas, Madrid, Castalia, 1982, pp. 191-207.

GÓMEZ-FERRER, Guadalupe, «Introducción», en PARDO BAZÁN, Emilia, La mujer española y otros escritos, GómEZ-FERRER, Guadalupe (ed.), Madrid, Cátedra, 1999, pp. 9-68.

GonzÁlez Herrán, José Manuel, Cristina Patiño Eirín y Ermitas Penas Varela (eds.), Actas del II Simposio Emilia Pardo Bazán: Los cuentos, A Coruña, CasaMuseo Emilia Pardo Bazán, 2006.

GonzÁlez Herrán, José Manuel, Cristina Patiño Eirín y Ermitas Penas Varela (eds.), Actas del IV Simposio «Emilia Pardo Bazán: Emilia Pardo Bazán y las artes del espectáculo». A Coruña, 25, 26, 27, 28 e 29 de xunio de 2007, A Coruña: Casa-Museo Emilia Pardo Bazán, 2008.

LATORRE, Yolanda, Musas trágicas. (Pardo Bazán y las artes), Lleida, Universitat de Lleida, Pagès Editors, 2002.

Pardo BAZÁn, Emilia, Una cristiana, en Obras completas, Madrid, Aguilar, tomo I, 1956.

PARdo BAZÁn, Emilia, La prueba, en Obras completas, Madrid, Aguilar, tomo I, 1956.

PatiÑo Eirín, Cristina, «Acerca del franciscanismo de Pardo Bazán», en ABuíN González, Anxo, Juan Casas Rigall y José Manuel González Herrán (eds.), Homenaje a Benito Varela Jácome, Universidade de Santiago de Compostela, 2001, pp. 455-75. 
PATIÑo EIRÍn, Cristina, «Por el arte: modelos vivos», en GOnZÁlez HerRÁn, José Manuel, Cristina Patiño Eirín y Ermitas Penas VAREla (eds.), La literatura de Emilia Pardo Bazán, Real Academia Galega, 2009, pp. 537-61.

Penas VARela, Ermitas, «El espacio en los cuentos de Emilia Pardo Bazán: una aproximación «, en GONZÁlez Herrán, José Manuel, Cristina PatiÑo Eirín y Ermitas Penas Varela (eds.), Actas del II Simposio Emilia Pardo Bazán: Los cuentos, A Coruña, Casa-Museo Emilia Pardo Bazán, 2006, pp. 153-74.

Peñalta CATAlán, Rocío, «El espacio urbano: de la metáfora a la significación. Una aproximación teórica», en Ciudad en obras. Metáforas de lo urbano en la literatura y en las artes, Eugenia Popeanga (coord.), Peter Lang, 2010, pp. 11-22.

Rodríguez, Adna Rosa, La cuestión feminista en los ensayos de Emilia Pardo Bazán, A Coruña, Edición do Castro/ensaio, 1991.

Rubio CRemades, Enrique, Panorama crítico de la novela realista-naturalista española, Madrid, Castalia, 2001.

SANTIÁÑEZ-TIÓ, Nil, «Entre el realismo y el modernismo: voz narrativa y deseo triangular en Una cristiana-La prueba», Castilla: Estudios de literatura, 19, 1994, pp. 187-205.

Fecha de recepción: 6-12-2011

Fecha de aceptación: 30-3-2012 